\title{
Percepção, compreensão e humanidade: os atos de linguagem e seus sujeitos
}

\author{
Daniele Gross Ramos ${ }^{1}$
}

CHARAUDEAU, Patrick. Linguagem e discurso: modos de organização. (Coordenação da equipe de tradução Ângela M. S. Corrêa \& Ida Lúcia Machado). São Paulo: Contexto, 2008.

A linguagem é fator determinante na existência humana, sendo a responsável pela comunicabilidade e, por conseqüência, pela vida em sociedade. Nas palavras de Patrick Charaudeau, autor do livro aqui apresentado, “A linguagem é um poder, talvez o primeiro poder do homem” (2008: 7).

Professor doutor de Ciências da Linguagem, na Universidade de Paris Nord e diretor do CAD (Centre d'Analyse du Discours) de Paris XIII, na França, Charaudeau é autor de, entre outras obras, Discurso das mídias, Discurso político e Dicionário de análise do discurso - este último em co-autoria com Dominique Maingueneau. Autor de uma Teoria Lingüística, esse importante estudioso da Análise do Discurso (AD) já se tornou conhecido entre os pesquisadores brasileiros da área.

Linguagem e discurso: modos de organização é resultado de um trabalho coletivo entre três laboratórios de pesquisa em $\mathrm{AD}$ e traz uma formulação inédita dos textos desse pesquisador, bem como novas atualizações e remodelizações de alguns de seus conceitos.

As organizadoras do livro, assim como seus tradutores, têm sólida formação na área da linguagem - o que resulta em um trabalho rico e bem estruturado, indo muito além de uma mera tradução dos textos do autor. Ao contrário, nesta obra - organizada especialmente para o público brasileiro -, os estudos de Charaudeau foram adaptados à nossa realidade. Muitos dos exemplos dados são de autores nacionais - e, quando não, a tradução é primorosa, permitindo que o leitor compreenda a contextualidade francesa - idioma original dos textos de Charaudeau.

A linguagem e seus atos, assim como sua inter-relacionalidade social, são tratados sob enfoques diversos, tanto nas artes, quanto na ciência. O filme de Werner Herzog, O Enigma de Kaspar Hauser, por exemplo, nos conta a história de um rapaz que é criado, até os 18 anos, dentro de um sótão sem contato humano algum. É através do olhar desse personagem que Izidoro Blikstein faz um ensaio acerca da relação entre linguagem, percepção, conhecimento e realidade. Esse ensaio nos traz a importância da linguagem sobre a percepção humana a respeito da realidade. "Conhecer o mundo pela linguagem, por signos lingüísticos, parece não bastar para dissolver o permanente mistério e a perplexidade do olhar de Kaspar Hauser. Talvez porque a significação do mundo deve irromper antes mesmo da codificação lingüística com que o recortamos: os significados já vão sendo desenhados na própria percepção/cognição da realidade” (BLIKSTEIN, 2003:17). 
E se a língua, na asserção de Mayra Rodrigues Gomes, funda "uma instituição social” (GOMES, 2000: $15)^{2}$, a linguagem "é o lugar que permite a troca significada na comunicação, não sendo, por isso mesmo, o instrumento da comunicação, pois vai muito além da mensagem comunicada. A linguagem é esse lugar em que o humano se torna humano e cada ato de linguagem é um testemunho da pertença de cada um à humanidade (...) (FREITAS, 2000: 97) .

Tema central de Linguagem e Discurso, o ato de linguagem é formado pela fala dos atos significadores ao mundo, considerando nesta fala as condições e a instância de sua transmissão. Possuidor de duas dimensões indissociáveis entre si (Explícito e Implícito), tal ato também é resultado de uma atividade estrutural (a Simbolização referencial - que tem como testemunha a dimensão do Explícito) e de uma outra serial (a Significação - esta ligada ao Implícito).

As interações ocorridas entre as duas dimensões também faz com que Charaudeau defina o fenômeno linguageiro como constituído por um duplo movimento: um exocêntrico, ligado à atividade serial que garante a produção da Significação do discurso (Implícito); e outro endocêntrico, que garante a construção do sentido da Simbolização referencial (Explícito) (2008: 27).

Patrick Charaudeau traz em Linguagem e discurso um esquema, abaixo reproduzido (2008: 77), sobre o ato de linguagem e seus sujeitos envolvidos no que ele denomina por "Situação de Comunicação".

O Ato de Linguagem e seus Sujeitos (reprodução)

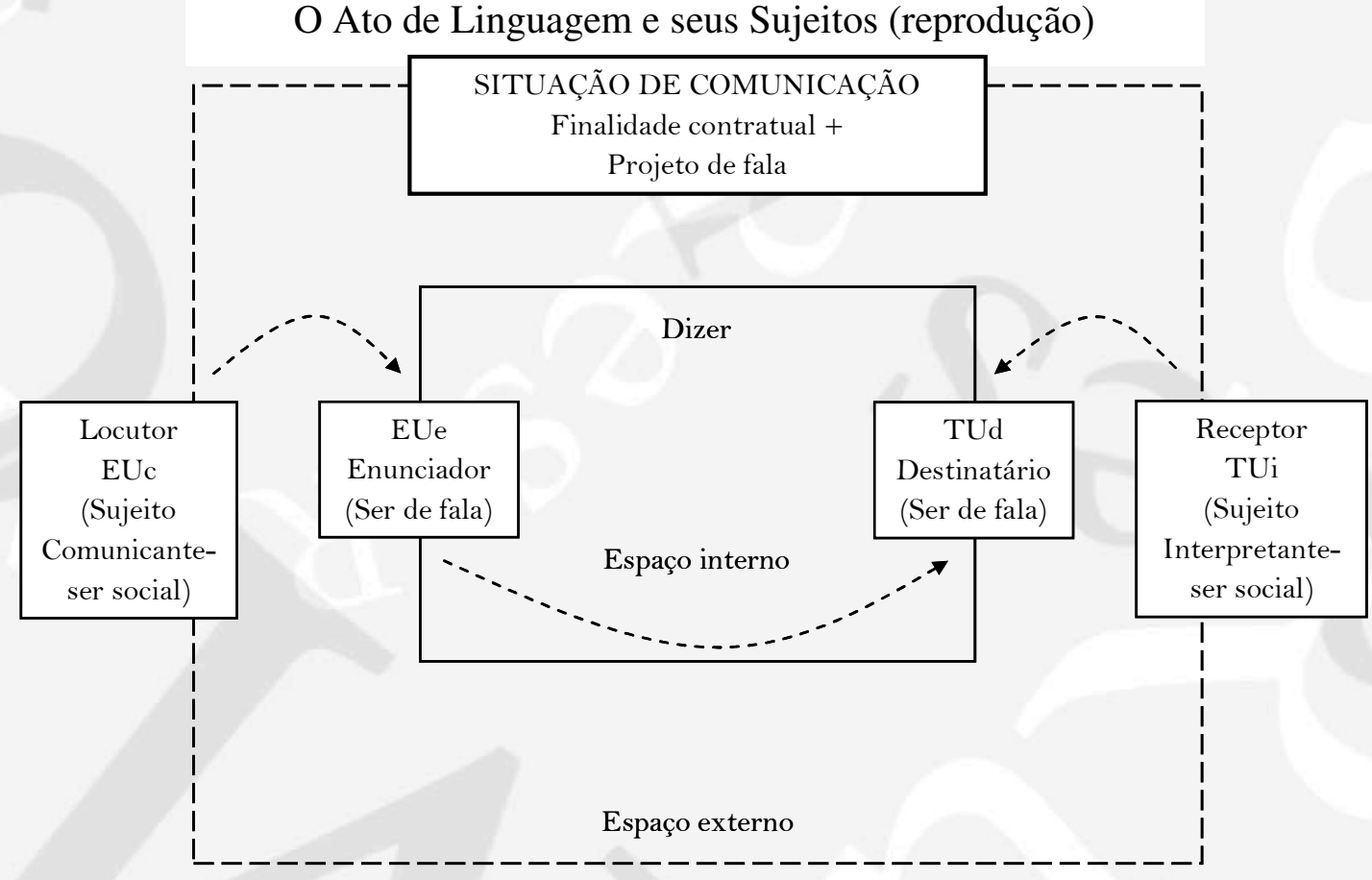


Tal situação possui dois espaços, um interno e outro externo, ambos envolvidos no circuito de produção e interpretação. A proposição apresentada pelo autor é de que todo ato de linguagem ocorrido entre dois interlocutores terá um desdobramento pelo efeito do discurso, que resulta em uma rede imaginária formada por quatro protagonistas - dois externos (reais) e dois imaginários (internos). Os sujeitos localizados no circuito externo são ativos: o EUc (Eu comunicante), o produtor da fala; e o TUi, o sujeito interpretante - que é real e se localiza fora do ato de enunciação daquele que produziu o enunciado (Euc). No outro circuito, o interno, TUd e EUe. O primeiro, o destinatário, está sempre presente, seja de forma implícita ou explícita - inclusive quando são vários os destinatários - e é um sujeito fabricado pelo Eu comunicante (EUc) e visto por este como um destinatário ideal e adequado ao seu ato de enunciação. Entretanto, esse destinatário idealizado é concretizado pelo TUi - e nem sempre coincide com aquele idealizado. No mesmo circuito, se encontra também o sujeito enunciador (EUe): uma imagem do enunciador criada pelo sujeito produtor da fala e subentendido na sua intencionalidade enquanto produtor (Euc). Ocorre também que, no momento em que a mensagem é interpretada (quando o TUi opera), é criada também uma imagem acerca do EUe - imagem esta configurada a partir do ato de fala deste último. TUd e EUe, sendo dois sujeitos imaginados, também existem dentro do ato de produção e interpretação, possuindo atribuições lingüísticas independentemente dos outros dois protagonistas do ato da linguagem - TUi e EUc, localizados no espaço externo do ato. Tal interpretação ${ }^{4}$ do esquema de Charaudeau também pode ser encontrada em FERREIRA (2001: 58 e 59).

Para identificar o sujeito enunciador, Patrick Charaudeau sugere que, ao invés de se perguntar "quem fala", deve-se procurar responder "quem o texto faz falar" ou "quais sujeitos o texto faz falar", visto que um ato de linguagem tem vários sujeitos (EUc-EUe; TUd-TUi) (2008: 63).

Tais importantes definições acerca dos atos de linguagem, bem como o papel de seus protagonistas nestes atos, constituem o conteúdo da primeira parte da obra em questão, intitulada "Uma problemática semiolingüística do estudo do discurso".

Além de buscar elucidar o ato de comunicação e a compreensão de seus protagonistas, Charaudeau demonstra detalhadamente a organização do discurso, seus princípios e modos e como estes se agrupam por meio das finalidades discursivas do ato de comunicação, foco de análise da segunda parte, "Os modos de organização do discurso". Dos quatro modos de organização do discurso apresentados (Enunciativo, Descritivo, Narrativo e Argumentativo), o autor destaca e justifica o posicionamento do Enunciativo ante os demais. O Modo Enunciativo tem uma vocação essencial, que é a de "dar conta da posição do locutor com relação ao interlocutor, a si mesmo e aos outros - o que resulta na construção de um aparelho enunciativo; por outro lado, e em nome dessa mesma vocação, esse Modo intervém na encenação de cada um dos três outros 
Modos de organização. E é por isso que se pode dizer que este Modo comanda os demais (...)" (CHARAUDEAU, 2008: 74).

É nesta segunda parte, que ocupa quase dois terços do livro, que o papel das organizadoras é ainda mais relevante. Após um primeiro capítulo, em que uma explicação acerca dos princípios de organização do discurso é apresentada, cada capítulo seguinte trata de um dos modos de organização demonstrado e ilustrado por meio de exemplos tirados da literatura e mídias nacionais diversas, contextualizando a análise e possibilitando que os leitores brasileiros experimentem, de fato, a Teoria Semiolinguística de Patrick Charaudeau.

Enfim, se é a linguagem o meio de representação de nosso pensamento e sociabilidade, importante se torna compreender seu funcionamento, tanto através de seus atos, como de seus protagonistas, bem como perceber de que forma se dá o funcionamento deste que, tal como a linguagem, também é uma atividade humana: o discurso.

\footnotetext{
${ }^{1}$ Bacharel em Comunicação Social, nas habilitações de Jornalismo e Rádio, TV \& Vídeo, é também especialista em Divulgação Científica pelo Núcleo José Reis (NJR), da Escola de Comunicação e Artes da Universidade de São Paulo (ECA/USP) e mestranda do programa de Ciências da Comunicação pela mesma instituição.

${ }^{2}$ GOMES, Mayra Rodrigues. Jornalismo e ciências da linguagem. São Paulo: Hacker Editores/Edusp, 2000.

${ }^{3}$ FREITAS, Jeanne-Marie Machado de. Posfácio. In: GOMES, Mayra Rodrigues. Jornalismo e ciências da linguagem. São Paulo: Hacker Editores/Edusp, 2000.

${ }^{4}$ FERREIRA, Jairo. "A significação em listas de discussão: uma análise do discurso". Colabora. Curitiba, vol.1, n.1, agosto 2001, p. 4-11.
} 